\title{
The Application of Complete Decongestive Therapy through Telephysiotherapy in the Treatment of Acute Upper Limb Lymphedema after Mastectomy during the COVID-19 Pandemic: A Case Study
}

\author{
Dimitrios Lytras $^{1 *}$ and loannis S. Myrogiannis ${ }^{2}$
}

*Correspondence: Iytrasde@gmail.com

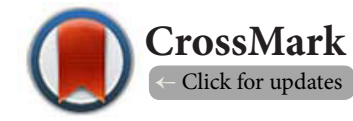

'Department of Physical Education and Sports Sciences, Aristotle University of Thessaloniki, 57001 Thermi Thessaloniki Greece. '2Laboratory of Hygiene-Medical Statistics, School of Medicine, Aristotle University of Thessaloniki, University Campus 54124, Thessaloniki, Greece.

\begin{abstract}
Background: This case report concerns the physiotherapy treatment of a 69-year-old woman with secondary arm lymphedema via teleconference. To date, no other lymphedema management through telephysiotherapy has been recorded.

Case presentation: The incident occurred last April (during the outbreak of COVID-19 pandemic). The ban on traffic combined with the lack of a specialized physiotherapist in the area where she lived led her to turn to our rehabilitation center. The communication was made by teleconference with the Skype application, where instructions were given to the patient for self-management of the lymphedema utilising self-Complete Decongestive Therapy (CDT). 10 on-line treatments were performed over a period of 15 days with one hour duration each. With the completion of the treatments the volume of the lymph was significantly reduced.
\end{abstract}

Conclusions: Telephysiotherapy could be beneficial for lymphedema patients. The application of self-CDT through telephysiotherapy can work educationally for the patient and promote the self-management of lymphedema.

Keywords: Case report, Lymphedema, Manual Lymphatic Drainage, Telerehabilitation

\section{Background}

The appearance of secondary arm lymphedema after mastectomy when it is accompanied by axillary lymph node clearance is the most common complication in the treatment of breast cancer in women and reaches 10 to $30 \%$ of breast cancer survivors [1-3]. The physiotherapy approach to lymphedema treatment includes lymphatic drainage (Manual Lymph Drainage, MLD), in which the movement and drainage of the lymph is achieved through gentle and rhythmic manual movements. In addition, it includes the use of bandaging in the area (Compression Therapy, $\mathrm{CT}$ ), skin care, as well as therapeutic exercise, thus forming the therapeutic regimen called Complete Decongestive Therapy (CDT). $[\mathbf{2}, \mathbf{4}, \mathbf{5}]$. Physiotherapeutic treatment of lymphedema is performed in two phases [6,7]. During the first phase (decongestion phase), through the CDT the lymph is drained and the volume of the lymphedema is reduced (this phase lasts 10-15 days). Then, while the reduction of the volume of the upper limb is achieved, the patient applies a compression garment - glove with the help of which the maintenance of the lymphedema is achieved at the same levels. The glove should be worn by the patient for life and should be replaced at regular intervals [7].

The effectiveness of CDT in reducing the volume of upper limb lymphedema in women after mastectomy has been confirmed in the past by many studies $[\mathbf{2}, \mathbf{4}, \mathbf{8}, \mathbf{9}]$. As part of the treatment as applied in clinical practice, physiotherapists who treat lymphedema often teach patients to perform selfmassage, exercise, and self-bandaging so that they can better manage their condition in the long run. Telephysiotherapy is a new way of physiotherapeutic approach that has been gaining ground in recent years. It has been widely applied in clinical 
practise, mainly in the performance of supervised exercises prescribed for musculoskeletal problems [10]. However, to date no other lymphedema management has been recorded through telephysiotherapy. Furthermore, the patient of this case reported not having followed any treatment for her arm lymphedema in the past. Telephysiotherapy was for her the first experience through which she actually dealt will her chronic problem and it took a lot of effort and patience on her side to follow our instructions. Thus, we considered it important to record this case.

\section{Case presentation}

\section{Case description}

The case involved a 69-year-old woman, a permanent resident of an Aegean island who was diagnosed with breast cancer 9 years ago and was treated with radiation and chemotherapy and had a left breast mastectomy and lymph node clearance. 15 months after surgery, she developed mild arm lymphedema (stage 3, according the, International Society of Lymphology, ISL), [11] without, however, having since followed any treatment.

In April 2020, during the outbreak of the COVID-19 pandemic in Greece, the woman suffered a generalized infection for which she had to be hospitalised for three days with extensive swelling all over her body. After the treatment of the infection and while the swelling in the rest of the body subsided, the volume of her affected limb increased greatly, falling to stage 4 [11] (Figure 1), and when she returned home, she had difficulty wearing a blouse or bending her elbow and was greatly prohibited in the execution of her daily activities.

Due to the ban on traffic due to the pandemic of COVID-19, in combination with the fact that there was no specialized physiotherapist for the management of lymphedema on the

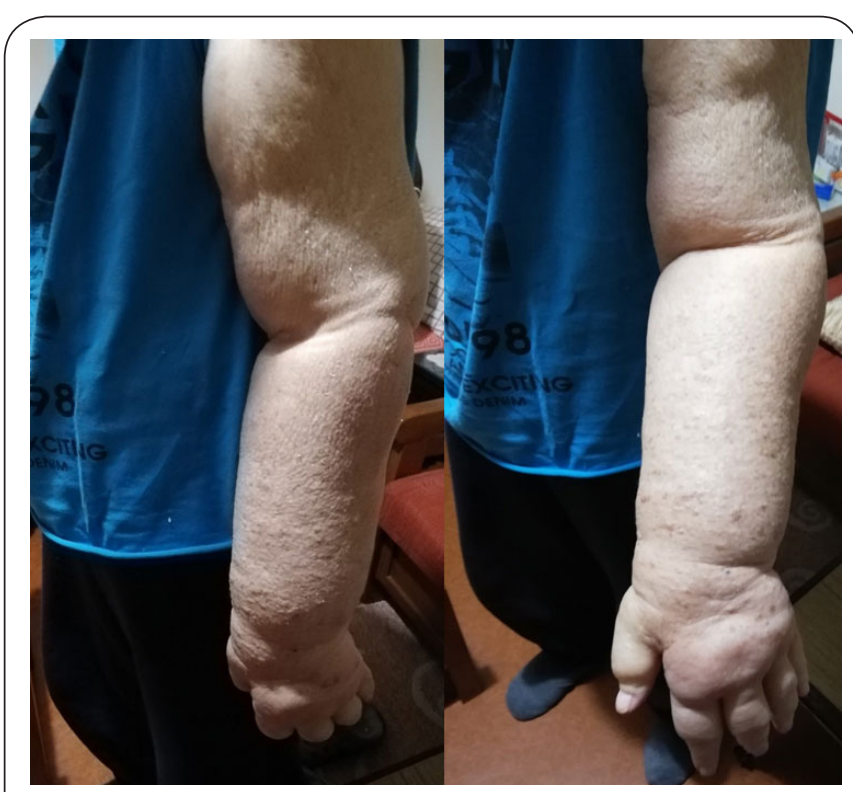

Figure 1. Left upper extremity lymphedema at base line measurement. island where she lived, she was forced to call our center to ask for help. In our effort to help her, we arranged a meeting by video conference in order to evaluate the patient and provide some advice. After consultation, it was consensually decided to undergo a series of on-line CDT treatments using the Skype application. These treatments were performed under the guidance of a specialized physiotherapist. In total, the woman attended 10 sessions lasting 60 minutes each, over a period of 15 days. Before starting the treatments, we took care to solve any problem of equipment adequacy, connectivity, etc. Furthermore, a suitable bandaging material was ordered and sent to her home and a professional nurse was asked to attend the woman's home during the first sessions.

\section{Intervention}

Each on-line session included the application of self-massage (self-MLD), the CT of the arm, skin care and the application of gentle exercises of the upper limb. The bandage had to be kept on for 24 hours until the next on-line session, while the woman was allowed to remove the bandage herself for only 10 to 15 minutes before the next session, in case she wanted to take a bath. Due to the fact that bandaging is, according to recent research, perhaps the most important part of treatment $[5,8]$ and in order to ensure that the right amount of bandage tension would be applied and there would be no unpleasant effects on the patient (from inappropriate very tight or very loose bandage), the help of the nurse of the island's health center was needed, who was present in the same room with the woman during the first 4 treatments. The nurse under the on-line guidance of the physiotherapist but also by being sent suitable educational video material to her mail, helped the woman to follow the instructions of the bandaging correctly and ensured as much as possible that the CT was appropriate.

Additionally, the same nurse performed the measurements of the perimeter of the upper limb with a tape measure at the reference points by filling in the appropriate measurement sheet (Figure 2). The measurements were performed before the start of the treatments, between the $7^{\text {th }}$ and the $8^{\text {th }}$ session and after the $10^{\text {th }}$ session. The measurement between the $7^{\text {th }}$ and $8^{\text {th }}$ session was made for the order of a special compression garment - glove, which was sent to her address after the completion of all 10 sessions, as 7 to 10 days were required for it to reach her. The specific time for measuring the glove was chosen because from the $1^{\text {st }}$ to the $7^{\text {th }}$ session the volume of the hand had been significantly reduced and on the other hand because we did not want to tire the patient with maintaining the bandage for more than 15 days. As such, our goal was for her to have obtained the glove by the completion of the 10 sessions. Each measurement was performed with on-line guidance by specialized individuals in the measurements to ensure the accuracy of the measurement.

\section{Self-MLD and skin care}

At the beginning of each session the patient was seated in 


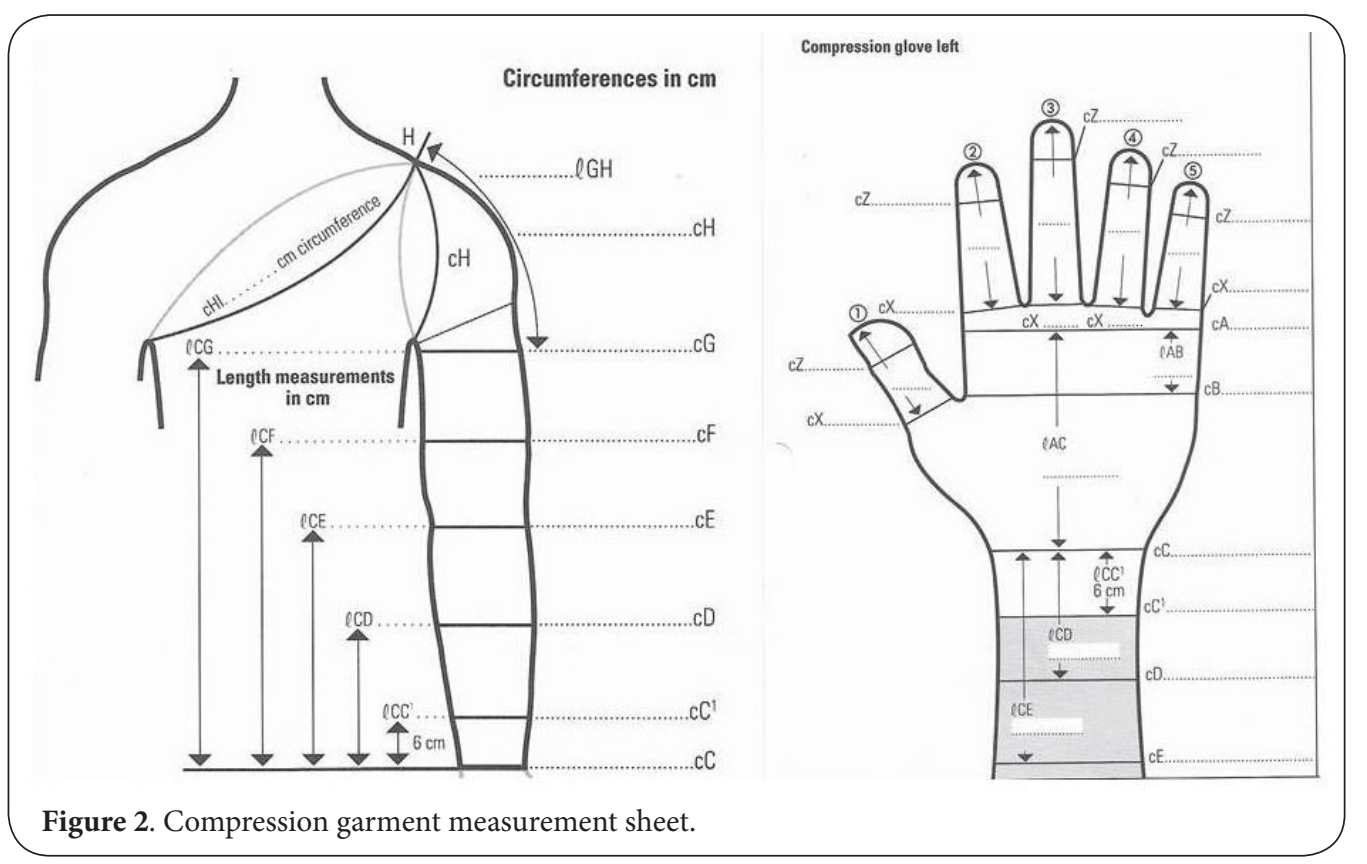

front of a desk on which the computer screen was located. Her hand rested on a pillow on top of the desk surface. The glenohumeral joint was in a position of slight flexion and abduction, while the other limb was performing the manipulations of the MLD. Each manipulation was performed slowly and repeated 15 times, encouraging the patient to count loudly while performing them. The self-MLD program included the following massage manipulations: stationary circles in the left supraclavicular fossa to the inferior deep cervical lymph nodes, stationary circles around the armpit area to the axillary lymph nodes, stationary circles and pump strokes on the front and outer surface of the arm, modified application of the scoop stroke (executed with the index finger and thumb) in the area of the triceps, stationary circles with the thumb in the area of the medial and lateral epicondyle of the elbow, stationary circles in the cubital fossa and in the anterior and posterior surface of the forearm, stationary circles in the area of the wrist, the fingers and the dorsal surface of the palm. Upon completion of the self-massage, the patient applied a moisturizer to the area of the hand to prevent dehydration of the skin.

\section{Self-CT}

After self-MLD, the self-CT was done with special short-stretch elastic compression bandages $(6,12)$. The following materials were used to bandage the upper limb: 1 upper limb jersey box (Tricofix), elastic $4 \mathrm{~cm}$ bandages for the fingers (Elastomul), $10 \mathrm{~cm}$ Artiflex substrate, two Comprilan $6 \mathrm{~cm}$ bandages, two Comprilan $8 \mathrm{~cm}$ bandages and a $10 \mathrm{~cm}$ Comprilan bandage. The bandaging was based on the instructions of Pritschow and Schuchhardt [7].

\section{Upper limb exercises}

The third part of the treatment included performing the exercises. The patient performed some very gentle range of motion exercises for the upper limb such as abduction with internal rotation and adduction with internal rotation of the glenohumeral joint, raising the affected hand above head height, exercises for the fingers with a gym ball etc.

\section{Results}

In the 10 treatments that took place over a period of 15 days, a very positive effect was noticed. The circumference of the upper limb was significantly reduced at all measurement points. More specifically, the upper arm circumference decreased from $30 \mathrm{~cm}$ to $26 \mathrm{~cm}$ after the $7^{\text {th }}$ session (reduction corresponding to $13.3 \%$ ), while it decreased further to $25 \mathrm{~cm}$ after the $10^{\text {th }}$ session (reduction corresponding to $16.6 \%$ ), the lower arm circumference decreased from $40.5 \mathrm{~cm}$ to $25.5 \mathrm{~cm}$ after the $7^{\text {th }}$ session (reduction corresponding to $37 \%$ ), while it decreased further in 24.5 after the $10^{\text {th }}$ session (reduction corresponding to $39,5 \%$ ), the upper forearm circumference decreased from $41 \mathrm{~cm}$ to $23 \mathrm{~cm}$ after the $7^{\text {th }}$ session (reduction corresponding to $43.9 \%$ ), while it decreased further to $22 \mathrm{~cm}$ after the $10^{\text {th }}$ session (reduction corresponding to $46.3 \%$ ), the wrist circumference decreased from $33.5 \mathrm{~cm}$ to $17.5 \mathrm{~cm}$ after the $7^{\text {th }}$ session (reduction corresponding to $47.7 \%$ ), while it decreased further to $16.5 \mathrm{~cm}$ after the $10^{\text {th }}$ session (reduction corresponding to $50.7 \%$ ), the palm circumference decreased from $25.5 \mathrm{~cm}$ to $17.5 \mathrm{~cm}$ after the $7^{\text {th }}$ session (reduction corresponding to $31.3 \%$ ), while it decreased further to $17 \mathrm{~cm}$ after the $10^{\text {th }}$ session (reduction corresponding to $33.3 \%$ ), (Figures 1-4).

\section{Discussion}

Concerning the first sessions, due to the unfamiliarity and 


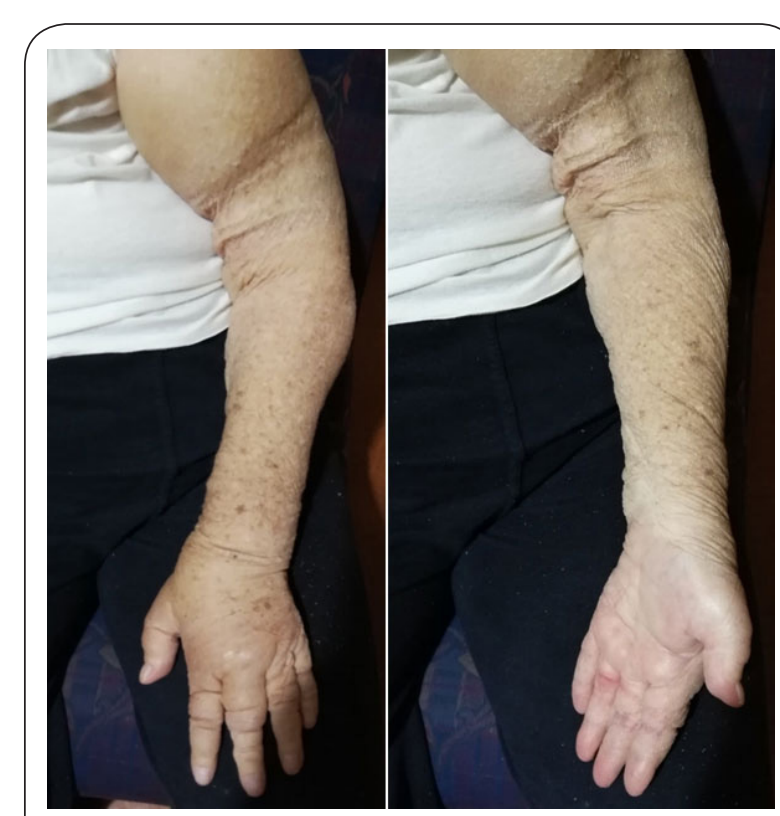

Figure 3. Left upper extremity lymphedema after 7 th session.

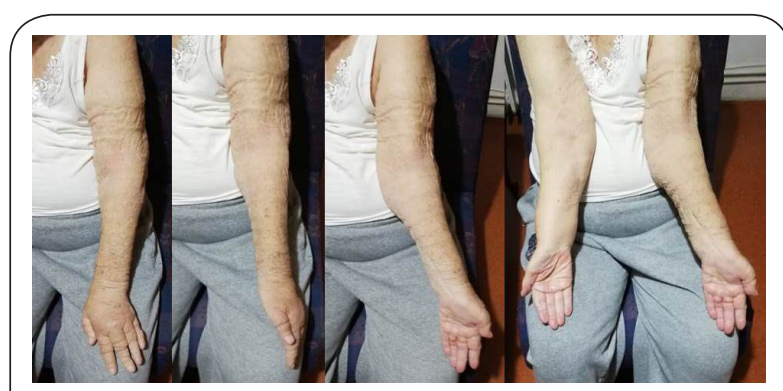

Figure 4. Left upper extremity lymphedema after 10th session.

the general difficulties presented by long-distance treatment, the patient had to be highly motivated extrinsically in order to implement the program properly. However, as she underwent the treatments, she became familiar with them, and in the last few sessions she had been trained to perform the program on her own, and the physiotherapist simply monitored the patient's treatment without much intervention. The patient herself was very satisfied with the whole process and according to her reports, the circumference of the hand was much smaller than before her hospitalization. At the end of the sessions, the patient had been provided with the arm compression sleeve and had been given all the proper instructions regarding its use.

The whole process was very constructive both for the patient herself and for us. As for the patient, the needs imposed by the specific circumstances led her to learn to manage her problem in the best way, taking into account that this process also worked educationally in the self-management of her problem. Until then, she had never had to go through this process, and perhaps in the context of "normal treatments" she would not have entered into this process of self-management to such an extent.

For us, who have not yet widely used telephysiotherapy in the treatment of lymphedema, it was a new experience and the fact that we were finally able to help this patient gave us the impetus to expand our professional horizons. In the future, we will be more determined and courageous in trying to deal remotely with similar cases with accessibility issues. The reservations and difficulties that presented in the beginning often made us unhappy. However, with our perseverance and patience we were able to get the desired result.

\section{Conclusions}

The general conclusion we have reached is that in order for telephysiotherapy to be grounded in clinical practice, established perceptions and mentalities need to be set aside and, in general, professionals need to take a more open look at new things to come.

\section{List of abbreviations \\ MLD: Manual Lymph Drainage \\ CT: Compression Therapy \\ CDT: Complete Decongestive Therapy}

\section{Competing interests}

The authors declare that they have no competing interests.

Authors' contributions

\begin{tabular}{|l|c|c|}
\hline Authors' contributions & LD & MI \\
\hline Research concept and design & $\checkmark$ & $\checkmark$ \\
\hline Collection and/or assembly of data & $\checkmark$ & $\checkmark$ \\
\hline Data analysis and interpretation & $\checkmark$ & $\checkmark$ \\
\hline Writing the article & $\checkmark$ & $\checkmark$ \\
\hline Critical revision of the article & $\checkmark$ & $\checkmark$ \\
\hline Final approval of article & $\checkmark$ & $\checkmark$ \\
\hline Statistical analysis & $\checkmark$ & $\checkmark$ \\
\hline
\end{tabular}

\section{Publication history}

Editor: Catherine Ortega, University of Texas Health Science Center, USA. Received: 24-July-2020 Final Revised: 02-Sept-2020

Accepted: 05-Sept-2020 Published: 19-Sept-2020

\section{References}

1. Basta MN, Wu LC, Kanchwala SK, Serletti JM, Tchou JC, Kovach SJ, et al. Reliable prediction of postmastectomy lymphedema: The Risk Assessment Tool Evaluating Lymphedema. Am J Surg [Internet]. 2017;213(6):1125-1133.e1. Available from: http://dx.doi.org/10.1016/j. amjsurg.2016.08.016

2. Ezzo J, Manheimer E, McNeely LM, Howell MD, Weiss R, Karin IJ, et al. Manual lymphatic drainage for lymphedema following breast cancer treatment. Cochrane Database Syst Rev. 2015;21(5):1-73.

3. DiSipio T, Rye S, Newman B, Hayes S. Incidence of unilateral arm lymphoedema after breast cancer: A systematic review and metaanalysis. Lancet Oncol [Internet]. 2013;14(6):500-15. Available from: http://dx.doi.org/10.1016/S1470-2045(13)70076-7

4. Hamner JB, Fleming MD. Lymphedema therapy reduces the volume of edema and pain in patients with breast cancer. Ann Surg Oncol. 
2007;14(6):1904-8.

5. McNeely ML, Magee DJ, Lees AW, Bagnall KM, Haykowsky M, Hanson $J$. The addition of manual lymph drainage to compression therapy for breast cancer related lymphedema: A randomized controlled trial. Breast Cancer Res Treat. 2004;86(2):95-106.

6. Internationa Lymphoedema Framework. Best Practice for the Management of Lympyoedema. International consensus [Internet]. Medical Education Partnership. London UK; 2006. Available from: https:// www.lympho.org/wp-content/uploads/2016/03/Best_practice.pdf

7. Pritschow $\mathrm{H}$, Schuchhardt $\mathrm{C}$. Lymphedema Management and Complete Physical Decongesitive Therapy : A Manual for Treatment. 2nd ed. Cologne: WPV; 2010.

8. Tambour M, Holt M, Speyer A, Christensen R, Gram B. Manual lymphatic drainage adds no further volume reduction to Complete Decongestive Therapy on breast cancer-related lymphoedema: a multicentre, randomised, single-blind trial. Br J Cancer [Internet]. 2018;119(10):121522. Available from: http://dx.doi.org/10.1038/s41416-018-0306-4

9. Shao $\mathrm{Y}$, Zhong DS. Manual lymphatic drainage for breast cancer-related lymphoedema. Eur J Cancer Care (Engl). 2017;26(5):1-5.

10. Holland AE. Telephysiotherapy: time to get online. J Physiother [Internet]. 2017;63(4):193-5. Available from: http://dx.doi.org/10.1016/j. jphys.2017.08.001

11. Cheng M-H, Chang D, Patel K. Principles and Practice of Lymphedema Surgery [Internet]. 1st ed. Oxford, United Kingdom.: Elsevier Ltd; 2015. Available from: https://books.google.com/books?id=0_ JwCgAAQBAJ\&pgis $=1$

12. Moffatt $\mathrm{C}$, Partsch $\mathrm{H}$, Schuren J, Quéré I, Sneddon $\mathrm{M}$, Flour $\mathrm{M}$, et al. Compression Therapy: A position document on compression bandaging. Medical Education Partnership. London UK; 2012.

\section{Citation:}

Lytras D and Myrogiannis IS. The Application of Complete Decongestive Therapy through Telephysiotherapy in the Treatment of Acute Upper Limb Lymphedema after Mastectomy during the COVID-19 Pandemic: A Case Study. Phys Ther Rehabil. 2020; 7:9.

http://dx.doi.org/10.7243/2055-2386-7-9 